\title{
Composition Control of Copolymer in Semibatch Emulsion Copolymerization I. Methyl Methacrylate/Styrene Two-Component System
}

\author{
Shih-Chang Hsu, Wen-Yen ChIU, ${ }^{\dagger}$ Chia-Fen LeE, ${ }^{*}$ and Herng-Show Chang ${ }^{* *}$ \\ Department of Chemical Engineering, National Taiwan University, Taipei, Taiwan, Republic of China \\ * Department of Cosmetic Science, Chia Nan College of Pharmacy and Science, Tainan, Taiwan, Republic of China \\ ${ }^{* *}$ Surface Technology and Coated Products Section New Materials Research and Development Department, \\ China Steel Corporation, Kaohsiung, Taiwan, Republic of China
}

(Received March 6, 2000; Accepted September 5, 2000)

\begin{abstract}
This research studies the Methyl methacrylate/Styrene two-component system through either soapless semi-batch emulsion copolymerization or soapless batch emulsion copolymerization. The optimal monomer feed flow rate was determined from experiments and theory through semi-batch emulsion copolymerization. The instantaneous composition of polymers was effectively controlled to get the desired final products. We used the monomer feed flow rate as a function of conversion, derived by Canu et al. from the monomer reactivity ratios and the interphase partition laws, along with the correspondence between conversion and time, to obtain the monomer feed flow rate as a function of time. The optimal monomer feed flow rate was obtained from iterative experiments, and through this we could effectively control the polymer composition.
\end{abstract}

KEY WORDS Two-Component/Semi-Batch / Emulsion Copolymerization /

Polymer latex is used widely for the applications in paint, textile coating, adhesives, and paper coating. Polymer latex of diverse properties is in great demand for different applications. It is critical to know how to get the desired copolymer latex by controlling polymer composition in a polymerization reaction.

Traditionally, polymer composition is controlled through semi-batch emulsion polymerization under a starved condition. ${ }^{1-5}$ In a reaction system like this, the composition of the monomer mixture is equal to the desired copolymer composition, with the monomer feed rate much lower than the polymerization rate. Since the monomers are added at slow rate, the composition of the copolymer obtained would be identical to that of the monomer mixture added to the reactor. Although the heat generated during reaction is easier to handle due to the slow reaction rate, it takes much longer time to complete the whole reaction. The low concentration of monomers throughout the entire reaction process changes the distribution of molecular weight, ${ }^{4}$ which would have further impact on the properties of the final product.

Therefore, researchers work hard to produce a copolymer with a given composition while keeping the polymerization rate maximum. To maintain the desired copolymer composition, we need to keep the corresponding monomer composition in the reaction under control by adding the monomers at an appropriate rate. To calculate the optimal monomer addition policy, we know what the time evolutions of both the number of polymer particles $\left(N_{\mathrm{p}}\right)$ and average number of free radicals per polymer particle $(\bar{n})$ are. Variation of the number of polymer particles during polymerization can be minimized in semi-batch seeded emulsion polymerization by adjusting the amount of surfactant. Average numbers of free radicals per polymer particle were determined by the rates of adsorption and desorption of the polymer particles

${ }^{{ }^{T}}$ To whom correspondence should be addressed. and bimolecular termination in the polymer particles. These values could not be accurately predicted and are usually unknown.

To solve this problem, Dimitratos et al..$^{6,7}$ proposed a polymerization rate model based on the equilibrium partition relationships and literature for evaluation of the average number of free radicals per polymer particle $(\bar{n})$. Model error was corrected by the compositions of monomers in the experiment. This model was further applied in a vinyl acetate (VAc)-butyl acrylate (BA) system.

Arzamendi and Asua ${ }^{8}$ proposed a semi-empirical model. In a semi-batch emulsion polymerization of the VAc-Methyl acrylate (MA) system, monomer feed rate was calculated by thermodynamic equilibrium equations. Through experiments, $\bar{n}$ was corrected by the product of volume fraction of polymer in latex particles and the square of particle diameter $\left(\phi_{\mathrm{p}}^{\mathrm{p}} \times d_{\mathrm{p}}^{2}\right)$. Adjusted $\bar{n}$ was used to calculate the monomer feed rate for the next run of experiment. Due to fast convergence, optimal monomer feed flow rate was obtained only after two or three iterative experiments.

Van Doremaele et al. ${ }^{9}$ made modification on Arzamendi and Asua's model, and applied it to the styreneMA system, where monomers exhibit largely different water solubility. They made an initial estimate of $\bar{n}$ to obtain the first addition policy. From conversion measured after each run, an improved monomer feed rate was calculated for subsequent runs using monomer interphase partition laws and reactivity ratios. Similarly, the optimal monomer feed rate was attained by iterative experiments.

The studies above only apply on a case-by-case basis, and can be used simply in a two-component system. Canu et al. ${ }^{10,11}$ proposed another model of more general application in 1994. They transformed the monomer feed rate from a function of time to a function of conversion. The optimal monomer feed rate was calculated through monomer interphase partition laws and reactivity ratios 
without estimate of $\bar{n}$, and no trial and error procedure was needed to get optimal monomer feed rate. As long as monomer interphase partition laws and reactivity ratios are known, this model may be applied in a system of any number of monomer species. In this approach, we no longer need to know how both the number of polymer particles $\left(N_{\mathrm{p}}\right)$ and average number of free radicals per polymer particle $(\bar{n})$ change over time. However, optimal monomer feed flow rate is a function of conversion in this model, and we need to monitor the on-line conversion throughout the entire experiment process, which makes it difficult for practical application. Therefore, in this work, we derived the correspondence equation of conversion vs. time and combined Canu's model to get the correlation between optimal monomer feed flow rate and time, as well as applications of the optimal monomer feed flow rate in multiple monomers systems.

\section{THEORETICAL TREATMENT}

Since the polymer composition has great influence on the properties of polymer products, desired polymer composition was obtained by controlling optimal monomer feed flow rate.

\section{Optimal Monomer Feed Flow Rate vs. Conversion}

Copolymer Composition vs. Conversion. Using the material balance of the $i$-th monomer species and polymer in a semi-batch reactor, the amount of $i$-th monomer, $M_{i}$, as a function of overall mass of polymer produced, $M_{\mathrm{c}}$, is given by ${ }^{10}$

$$
\frac{\mathrm{d} M_{i}}{\mathrm{~d} M_{\mathrm{c}}}=\hat{Q}_{i}-Y_{i} \quad i=1 \cdots N_{m}
$$

where $Y_{i}$ is the weight fraction of monomer $i$ in the polymer, $\hat{Q}_{i}$ is mass of monomer $i$ fed to reactor per unit mass of polymer produced, and $N_{m}$ is the number of monomer species.

To get the monomer feed flow rate $v s$. conversion from eq 1, Canu et al.$^{10,11}$ used monomer interphase partition laws and monomer reactivity ratios. The monomer in the reactor is partitioned among three phases, i.e., polymer particles, oil droplet and water phase, so that

$$
M_{i}=M_{i}^{\mathrm{p}}+M_{i}^{\mathrm{d}}+M_{i}^{\mathrm{w}} \quad i=1 \cdots N_{m}
$$

where $M_{i}^{l}$ is the amount of monomer $i$ in phase $l$.

Optimal Monomer Feed Flow Rate us. Conversion. There are two intervals of emulsion polymerization: the first interval with monomer droplets called "the flooded interval", and the second interval when monomer droplets disappear, "the starved interval".

Flooded Interval. Based on eq 1 and the monomer interphase partition law, ${ }^{10}$ we obtain

$$
\hat{Q}_{i}=Y_{i}+\rho_{i} C_{i}\left(\frac{\mathrm{d} V_{\mathrm{d}}}{\mathrm{d} M_{\mathrm{c}}}+\frac{\phi^{*}}{\rho_{\mathrm{c}}\left(1-\phi^{*}\right)}\right)
$$

$$
=Y_{i}+\frac{Y_{i}}{A_{i}}\left(\rho_{\mathrm{c}} \frac{\mathrm{d} V_{\mathrm{d}}}{\mathrm{d} M_{\mathrm{c}}}+\frac{\phi^{*}}{\left(1-\phi^{*}\right)}\right)
$$

where $A_{i}=\rho_{\mathrm{c}} Y_{i} / \rho_{i} C_{i}, C_{i}$ is the polymer free volume fraction of monomer $i$ in polymer particles, $\rho_{i}$ is density of monomer $i, \rho_{\mathrm{c}}$ is copolymer density, $V_{\mathrm{d}}$ is volume of monomer droplet, and $\phi^{*}$, overall volume fraction of monomer species at saturation in polymer particles.

Since $V_{\mathrm{d}}$ is a function of $M_{\mathrm{c}}$ in eq 3 , we adopted the semi-starved process. In the semi-starved process, one monomer ( $j$ monomer) was fed all at once at the beginning of the reactor with the remaining monomers gradually over time. In such a case, eq 3 is,

$$
\begin{aligned}
\hat{Q}_{i} & =Y_{i}-\frac{\rho_{i} C_{i}}{\rho_{j} C_{j}} Y_{j} \\
& =\frac{Y_{i}}{A_{i}}\left(A_{i}-A_{j}\right) \quad \text { for } i \neq j
\end{aligned}
$$

To get positive monomer feed flow rates of the remaining monomer species based on eq 4 , the $j$-th monomer should possess the smallest parameter $A_{j}$. From the definition of $A_{i}$, we know that $A_{i}$ is proportional to the propagation rate constant $\overline{k_{\mathrm{p} i}}$. Therefore, we identify the $j$-th monomer, the least reactive monomer, by calculating $A_{i}$. So each kind of monomer, except for the one with the smallest reactivity, is fed to the reactor in a way based on eq 4.

Starved Interval. When no monomer droplets are present $\left(V_{\mathrm{d}}=0\right)$, the reactor operates in the starved interval. From eq 1, together with monomer interphase partition laws, we obtain an equation of monomer feed flow rate, as eq $5 .^{10}$

$$
\hat{Q}_{i}=Y_{i}+\frac{Y_{i}}{A_{i}}\left[\frac{\mathrm{d} \phi}{\mathrm{d} M_{\mathrm{c}}}\left(B_{i}+\frac{M_{\mathrm{c}}}{(1-\phi)^{2}}\right)+\frac{\phi}{(1-\phi)}\right]
$$

where $B_{i}=\frac{\rho_{\mathrm{c}} M_{i}^{\mathrm{w}}}{\rho_{i} \phi_{i}}=\frac{\rho_{\mathrm{c}} M_{i}^{\mathrm{w}, *}}{\rho_{i} \phi^{*}}$, representative of monomer solubility in the aqueous phase, $M_{i}^{\mathrm{w}}$ is the amount of

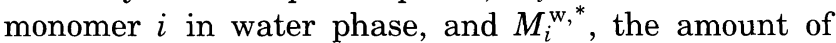
monomer $i$ in water phase at saturation, $\phi_{i}$ is the volume fraction of monomer $i$ in polymer particles, and $\phi$ is the overall volume fraction of monomer species in polymer particles.

Since $\phi$ is a function of $M_{\mathrm{c}}$ in eq 5 , we choose $\hat{Q}_{j}$ for a particular monomer species to solve $\phi$ and compute $\hat{Q}_{i}$ for all remaining monomers. We stopped the feed of the $j$-th one monomer species $\left(\hat{Q}_{j}=0\right)$ in the starved interval, and the remaining monomers were fed into the system gradually over time. In such case, eq 5 could lead to ${ }^{10}$

$$
\frac{\mathrm{d} \phi}{\mathrm{d} M_{\mathrm{c}}}=-\frac{A_{j}(1-\phi)^{2}+\phi(1-\phi)}{B_{j}(1-\phi)^{2}+M_{\mathrm{c}}}=-r_{j}
$$

where the new parameter $r_{j}$ is introduced. Integrated with the final condition: 


$$
\phi=0 \quad M_{\mathrm{c}}=M_{\mathrm{c}}^{\mathrm{f}}
$$

where $M_{\mathrm{c}}^{\mathrm{f}}$ is the total mass of polymer produced, we obtain,

$$
\begin{aligned}
& \phi\left(M_{\mathrm{c}}\right)=\frac{D_{j}-\left[D_{j}^{2}-4 B_{j} A_{j}\left(M_{\mathrm{c}}^{\mathrm{f}}-M_{\mathrm{c}}\right)\right]^{\frac{1}{2}}}{2 B_{j}} \\
& D_{j}=A_{j}\left(M_{\mathrm{c}}^{\mathrm{f}}-M_{\mathrm{c}}\right)+M_{\mathrm{c}}+B_{j}
\end{aligned}
$$

By substituting eq 6 into eq 5 , we obtained,

$$
\hat{Q}_{i}=\frac{Y_{i}}{A_{i}}\left(B_{i}+\frac{M_{\mathrm{c}}}{(1-\phi)^{2}}\right)\left(r_{i}-r_{j}\right) \quad \text { for } i \neq j
$$

To get positive monomer feed flow rates of the remaining monomer species based on eq 9 , the $j$-th monomer should have the smallest parameter $\gamma_{j}$, hereafter referred to as the critical monomer. In this research, since methyl methacrylate (MMA) has the smallest $\gamma_{j}$, it served as the critical monomer in both systems with weight ratios of Styrene to MMA is 5:5 and 3:7. Please refer to Canu's mode ${ }^{10}$ for more details about the theory. After the critical monomer was determined, each monomer, except for the critical one, could be fed into the reactor based on the calculations of eq 9 .

Moreover, the transition from the flooded to starved interval occurred when the polymer produced was equal to,

$$
M_{\mathrm{c}}^{*}=\frac{M_{\mathrm{c}}^{\mathrm{f}} A_{j}-B_{j} \phi^{*}}{A_{j}+\frac{\phi^{*}}{1-\phi^{*}}}
$$

\section{Conversion vs. Time}

Assuming that in emulsion polymerization, reaction only takes place in the polymer particles, and the latex is monodisperse, the rate of consumption of monomer $i$ may be expressed as follows:

$$
R_{\mathrm{c} i}=\overline{k_{\mathrm{p} i}} \bar{n}\left[M_{i}\right]^{\mathrm{p}} \frac{N_{\mathrm{p}}}{N_{\mathrm{A}}}
$$

where $R_{\mathrm{c} i}$ is the overall rate of monomer $i$ consumption, $\overline{k_{\mathrm{p} i}}$ average propagation rate constant, $\bar{n}$ the average number of radicals per polymer particle, $\left[M_{i}\right]^{p}$ the concentration of monomer $i$ in polymer particle, $N_{\mathrm{p}}$ the number of particles per unit volume of water phase, and $N_{\mathrm{A}}$ Avogadro's number.

The rate of formation of the polymer may thus be expressed as:

$$
R_{\mathrm{c}}=\sum_{i=1}^{N_{m}} R_{\mathrm{c} i}=\left(\sum_{i=1}^{N_{m}} \overline{k_{\mathrm{p} i}}\left[M_{i}\right]^{\mathrm{p}}\right) \bar{n} \frac{N_{\mathrm{p}}}{N_{\mathrm{A}}}
$$

where $R_{\mathrm{c}}$ is the overall polymerization rate.

Using mass balance of polymer, we get

$$
\frac{\mathrm{d} M_{\mathrm{c}}}{\mathrm{d} t}=V_{\mathrm{w}} \sum_{i=1}^{N_{m}} R_{\mathrm{c} i} M W_{i}
$$

where $V_{\mathrm{w}}$ is the overall volume of water phase, and $M W_{i}$, the molecular weight of monomer $i$.

By substituting eq 11 into eq 13, conversion and time are related by:

$$
\frac{\mathrm{d} M_{\mathrm{c}}}{\mathrm{d} t}=V_{\mathrm{w}}\left(\sum_{i=1}^{N_{m}} \overline{k_{\mathrm{p} i}}\left[M_{i}\right]^{\mathrm{p}} M W_{i}\right) \frac{\bar{n} N_{\mathrm{p}}}{N_{\mathrm{A}}}
$$

where $\overline{k_{\mathrm{p} i}},\left[M_{i}\right]^{\mathrm{p}}, \bar{n}$, and $N_{\mathrm{p}}$ is obtained as follows:

(1)average propagation rate constant $\left(\overline{k_{\mathrm{p} i}}\right)$

Average propagation rate constant is obtained while determining $C_{i}$. In the system, the instantaneous molar composition of the copolymers is expressed $\operatorname{as}^{10}$ :

$$
y_{i}=\frac{R_{\mathrm{c} i}}{R_{\mathrm{c}}}=\frac{\overline{k_{\mathrm{p} i}}\left[M_{i}\right]^{\mathrm{p}}}{\sum_{j}^{N_{m}} \overline{k_{\mathrm{p} j}}\left[M_{j}\right]^{\mathrm{p}}}
$$

The concentration of monomer $i$ in polymer particle is:

$$
\left[M_{i}\right]^{\mathrm{p}}=C_{i} \phi \tilde{\rho_{j}}
$$

where $\tilde{\rho}_{i}$ is the molar density of monomer $i$.

Substituting eq 16 into eq 15 leads to,

$$
C_{i}=y_{i} \frac{\sum_{j}^{N_{m}} \overline{k_{\mathrm{p} j}} C_{j} \tilde{\rho}_{j}}{\overline{k_{\mathrm{p} i}} \tilde{\rho_{i}}}
$$

For only two monomers in the system, eq 17 is simplified into:

$$
\frac{y_{1}}{y_{2}}=\frac{\overline{k_{\mathrm{p} 1}} \widetilde{\rho_{1}} C_{1}}{\overline{k_{\mathrm{p} 2}} \widetilde{\rho}_{2} C_{2}}=\mathrm{constant}
$$

where the average propagation rate constant is expressed as,

$$
\begin{aligned}
& \overline{k_{\mathrm{p} 1}}=k_{\mathrm{p} 11} P_{1}+k_{\mathrm{p} 21} P_{2} \\
& \overline{k_{\mathrm{p} 2}}=k_{\mathrm{p} 12} P_{1}+k_{\mathrm{p} 22} P_{2}
\end{aligned}
$$

where $P_{i}$ is the probability of a growing radical with terminal unit of type $i$ as

$$
\begin{aligned}
& P_{1}=\frac{k_{\mathrm{p} 21} C_{1} \tilde{\rho}_{1}}{k_{\mathrm{p} 21} C_{1} \tilde{\rho}_{1}+k_{\mathrm{p} 12} C_{2} \tilde{\rho}_{2}} \\
& P_{2}=\frac{k_{\mathrm{p} 12} C_{2} \widetilde{\rho}_{2}}{k_{\mathrm{p} 21} C_{1} \widetilde{\rho_{1}}+k_{\mathrm{p} 12} C_{2} \widetilde{\rho}_{2}}
\end{aligned}
$$

Using eqs $18,19,20$, and consistency condition " $C_{1}+$ $C_{2}=1$ ", we get analytical solution for $C_{1}$ or $C_{2}$. Average propagation rate constant could also be determined. 
(2) The concentration of monomer $i$ in polymer particles $\left(\left[M_{j}\right]^{\mathrm{p}}\right)$

Flooded Interval. When monomer droplets are present, polymer particles are saturated with monomers, i.e., the concentration of monomers in latex particles is constant. So we calculated overall volume fraction of monomers in polymer particles with $\phi_{i}^{*, 0}$, the volume fraction of the pure monomer in polymer particles, and the equation, $\phi^{*}=\sum_{i}^{N_{m}} y_{i} \phi_{i}^{*, 0}$. The concentration of monomer $i$ in polymer particles is obtained by eq 16 .

Starved Interval. With the disappearance of monomer droplets, the concentration of monomers in polymer particles is no longer constant, rather a function of conversion $\left(M_{\mathrm{c}}\right)$ [cf. eq 8 ].

Therefore, after we found the overall volume fraction of monomers in polymer particles at the starved interval, the concentration of monomer $i$ in polymer particles could was obtained by eq 16 .

(3) The number of particles per unit volume of water phase $\left(N_{\mathrm{p}}\right)$

For seeded emulsion polymerization, we ignore the possibility of secondary nucleation, and assume that the number of particles is identical to that of seed particles. However, if no seeds are used at first, we neglect the nucleation stage, and use the number of particles of the final latex.

(4) Average number of radicals per polymer particle $(\bar{n})$

First, we estimated initial average number of free radicals in latex particles (e.g., 0.5).

After substituting the values based on (1)-(4) into eq 14 , we found correlation between conversion and time. $N_{\mathrm{p}}$ and $\bar{n}$ were estimated, and thus should be further verified to obtain the correlation with time by experiment.

\section{Monomer Feed Flow Rate vs. Time}

We obtained an initial monomer feed flow rate as a function of time by eqs 4,9 , and 14 . The first experiment was based on initial monomer feed flow rate, and a new correlation between conversion and time was obtained. With this conversion-time correlation, and eqs 4 and 9, the monomer feed flow rate was obtained. By experiment, we found optimal monomer feed flow rate, whose flow chart is shown in Figure 1.

MMA/Styrene two-component system was obtained using semi-batch soapless emulsion copolymerizaton or batch soapless emulsion copolymerizaton.

\section{Numerical Values of the Model Parameters}

To get optimal monomer feed flow rate, the parameters calculation include physical properties of monomers and polymers, reactivity ratio of monomers, and partition of monomers in each phase. These parameters are shown in Table I.

Optimal Monomer Feed Flow Rate vs. Conversion. With constant instantaneous composition $\left(Y_{i}\right)$ and the parameters in Table I, we obtained polymer free volume fraction of monomer $i$ in polymer particles $\left(C_{i}\right) . A_{i}$ and $B_{i}$ were found by $C_{i}$ and the correlation between optimal monomer feed rate and conversion [see eq 5 and eq 11] was obtained.
Table I. Values of model parameters

\begin{tabular}{|c|c|c|}
\hline Parameter & Numerical value & Reference \\
\hline \multicolumn{3}{|l|}{ Reactivity ratios } \\
\hline$r_{12}$ & 0.52 & 12 \\
\hline$r_{21}$ & 0.46 & 12 \\
\hline \multicolumn{3}{|c|}{ Monomer concentrations in aqueous phase at saturation $/ \mathrm{mol} \mathrm{L}^{-1}$} \\
\hline$M_{1}^{\mathrm{w},{ }^{*}}$ & $3.65 \times 10^{-3}$ & 13 \\
\hline$M_{2}^{\mathrm{w}, *}$ & $1.60 \times 10^{-1}$ & 13 \\
\hline \multicolumn{3}{|c|}{ Monomer densities/g $\mathrm{cm}^{-3}$} \\
\hline$\rho_{1}$ & 0.909 & \\
\hline$\rho_{2}$ & 0.945 & \\
\hline \multicolumn{3}{|c|}{ Copolymer density (average value) $/ \mathrm{g} \mathrm{cm}^{-3}$} \\
\hline$\rho_{\mathrm{c}}$ & 1.1 & 12 \\
\hline \multicolumn{3}{|c|}{$\begin{array}{l}\text { Monomer concentrations in particles at saturation (volume frac- } \\
\text { tion) }\end{array}$} \\
\hline$\phi_{1}^{*, 0}$ & 0.6 & 13 \\
\hline$\phi_{2}^{*, 0}$ & 0.71 & 13 \\
\hline \multicolumn{3}{|c|}{ Molecular Weight/g mol ${ }^{-1}$} \\
\hline$M_{1}$ & 104 & \\
\hline$M_{2}$ & 100 & \\
\hline
\end{tabular}

$(1=$ Styrene, $2=$ MMA $)$

Table II. Parameters for calculation of correlation between optimal monomers feed rate and conversion for semi-batch reaction of Styrene and MMA with a weight ratio of 3:7 (5:5)

\begin{tabular}{|c|c|c|c|}
\hline Monomer & Styrene & MMA & Annotation \\
\hline$Y_{i}^{\mathrm{a}}$ & $0.3(0.5)$ & $0.7(0.5)$ & Desired \\
\hline$C_{i}$ & $0.221(0.489)$ & $0.779(0.511)$ & \\
\hline$\phi^{*}$ & \multicolumn{2}{|c|}{$0.677(0.655)$} & $\phi^{*}=\sum_{i} y_{i} \phi_{i}^{*, 0}$ \\
\hline$\phi$ & \multicolumn{2}{|c|}{$0.677-0(0.655-0)$} & eq 8 \\
\hline$\gamma_{i}$ & $\begin{array}{c}0.0142-0.0163 \\
(0.0119-0.0123)\end{array}$ & $\begin{array}{c}0.0108-0.0082 \\
(0.0104-0.0089)\end{array}$ & eq 6 \\
\hline$A_{i}$ & $\begin{array}{c}1.643 \\
(1.237)\end{array}$ & $\begin{array}{c}1.046 \\
(1.139)\end{array}$ & $A_{i}=\frac{\rho_{\mathrm{c}} Y_{i}}{\rho_{i} C_{i}}$ \\
\hline$B_{i}$ & $\begin{array}{c}0.679 \\
(0.701)\end{array}$ & $\begin{array}{c}27.510 \\
(28.434)\end{array}$ & $B_{i}=\frac{\rho_{\mathrm{c}} M_{i}^{\mathrm{w}}}{\rho_{i} \phi_{i}}=\frac{\rho_{\mathrm{c}} M_{i}^{\mathrm{w},}}{\rho_{i} \phi^{*}}$ \\
\hline$\hat{Q}_{i}^{\mathrm{fb}}[\mathrm{g} / \mathrm{g}]$ & $\begin{array}{c}0.109 \\
(0.0398)\end{array}$ & $\begin{array}{c}0 \\
(0)\end{array}$ & eq 4 \\
\hline$\hat{Q}_{i}^{\mathrm{s} \mathrm{c}}[\mathrm{g} / \mathrm{g}]$ & $\begin{array}{c}0.1621-0.1492 \\
(0.1562-0.1390)\end{array}$ & $\begin{array}{c}0 \\
(0)\end{array}$ & eq 9 \\
\hline$M_{i}^{\mathrm{od}}[\mathrm{g}]$ & $\begin{array}{l}15.79 \\
(38.7)\end{array}$ & $\begin{array}{c}70 \\
(50)\end{array}$ & $\begin{array}{l}M_{i}^{0}= \\
\quad Y_{i} \times M_{\mathrm{c}}^{\mathrm{f}}-\int \hat{Q}_{i}^{\mathrm{f}}-\int \hat{Q}\end{array}$ \\
\hline
\end{tabular}

a The total mass of polymer produced $\left(M_{\mathrm{c}}^{\mathrm{f}}\right): 100 \mathrm{~g} .{ }^{\mathrm{b}}$ Monomer feed flow rate in flooded interval. ${ }^{c}$ Monomer feed flow rate in starved interval. ${ }^{\mathrm{d}}$ Amount of monomer to be charged initially into the reactor.

In the two-component system of Styrene and MMA, we changed the weight ratio of monomers to get two polymers with weight ratios of Styrene to MMA of 5:5 and 3:7.

The parameters and results for calculating the correlation between optimal monomer feed flow rate and conversion for the two component system of styrene and MMA are shown in Table II.

From Table II, in the MMA/Styrene two-component system, $A_{i}$ of Styrene was higher than that of MMA in both systems where the weight ratio of Styrene and 


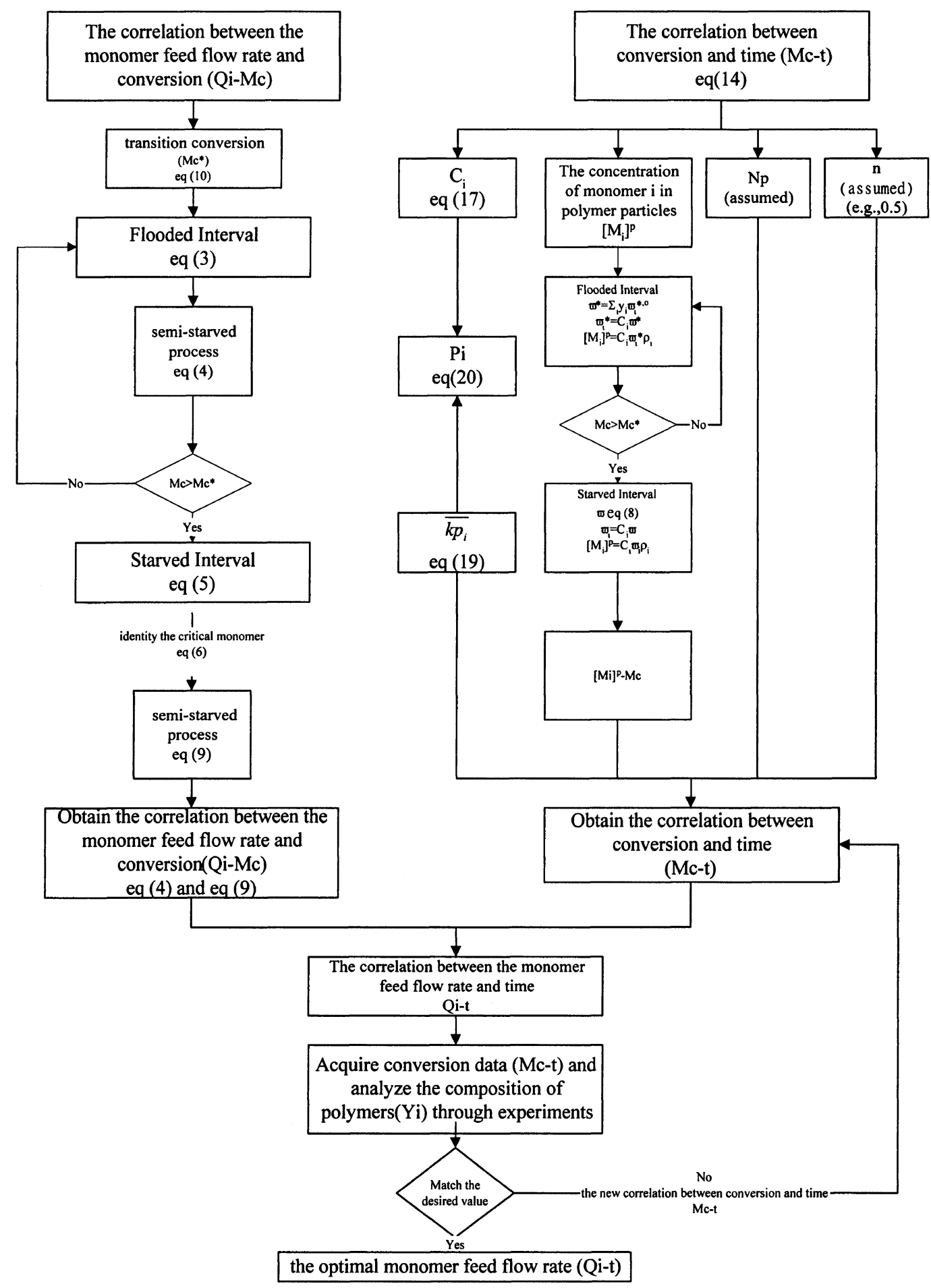

Figure 1. Flow chart of iteration procedure for determination of optimal monomer flow rate.

MMA monomers was 5:5 or 3:7. Therefore in the flooded interval, all MMA monomers and part of the Styrene should perhaps be charged in the reactor at the beginning of the flooded interval, while the rest of Styrene may be fed gradually. Similarly in the starved interval, with eq 9, we found that $\gamma_{i}$ of Styrene was higher than that of MMA. Since MMA served as the critical monomer at this stage, we should also feed Styrene into the reactor gradually.

Conversion vs. Time. The correlation between conver- sion and time for semi-batch reaction was obtained through eq 14. The parameters for getting the correlation between conversion and time for the Styrene/MMA two-component system with weight ratios of Styrene to MMA of 5:5 and 3:7 are listed in Table III.

Though we obtained the correlation between conversion and time by Table III, the first derived correlation may not be appropriate. This is because $N_{\mathrm{p}}$ and $\bar{n}$ are estimated, and hence should be further modified by experiment to get the correct value. 
Table III. Parameters for calculation of correlation between conversion and time for semi-batch reaction of Styrene and MMA with weight ratio of $3: 7(5: 5)$

\begin{tabular}{|c|c|c|c|}
\hline Monomer & Styrene & MMA & Annotation \\
\hline $\mathrm{Temp} /{ }^{\circ} \mathrm{C}$ & \multicolumn{2}{|c|}{70 or 80} & Desired \\
\hline$\overline{k_{\mathrm{p} i}} / \mathrm{cm}^{3} \mathrm{~mol}_{-\mathrm{sec}^{-1}}$ & $\begin{array}{c}1465 \text { or } 1116 \\
(1086)\end{array}$ & $\begin{array}{c}931 \text { or } 709 \\
(1001)\end{array}$ & \\
\hline$\left[M_{i}\right]^{\mathrm{p}, \mathrm{f} \mathrm{a}} / \mathrm{mol} \mathrm{cm}^{-3}$ & $\begin{array}{c}0.0013 \\
(0.0028) \\
\end{array}$ & $\begin{array}{c}0.0050 \\
(0.0032) \\
\end{array}$ & {$\left[M_{i}\right]^{\mathrm{p}}=C_{i}{\widetilde{\rho_{i}}} \phi^{*}$} \\
\hline$\left[M_{i}\right]^{\mathrm{p}, \mathrm{s} \mathrm{b}} / \mathrm{mol} \mathrm{cm}^{-3}$ & $\begin{array}{c}0.0013-0 \\
(0.0028-0)\end{array}$ & $\begin{array}{c}0.0050-0 \\
(0.0032-0)\end{array}$ & {$\left[M_{i}\right]^{\mathrm{p}}=C_{i} \widetilde{\rho_{i}} \phi$} \\
\hline$M W_{i} / \mathrm{g} \mathrm{mol}^{-1}$ & 104 & 100 & Table I \\
\hline$N_{\mathrm{p}} /$ particles cm $^{-3}$ & \multicolumn{2}{|c|}{$2 \times 10^{13}$} & First try \\
\hline $\bar{n}$ & \multicolumn{2}{|c|}{0.5} & First try \\
\hline$V_{\mathrm{w}} / \mathrm{cm}^{3}$ & \multicolumn{2}{|c|}{1000} & Desired \\
\hline
\end{tabular}

${ }^{a}$ Concentration of monomer $i$ in polymer particles in flooded interval. ${ }^{\mathrm{b}}$ Concentration of monomer $i$ in polymer particles in starved interval.

\section{EXPERIMENTAL SECTION}

\section{Materials}

MMA and Styrene were distilled under nitrogen atmosphere and reduced pressure prior to polymerization. Other materials were of analytical grade and used without further purification.

\section{Ingredients and Conditions for Polymerization}

Semi-batch Soapless Emulsion Copolymerization. In semi-batch emulsion polymerization, copolymer latex particles were synthesized via soapless emulsion polymerization. The ingredients and conditions for both twocomponent systems are given in Table IV.

Batch Soapless Emulsion Copolymerization. In the batch emulsion polymerization, the copolymer latex particles were synthesized via soapless emulsion polymerization. The ingredients and conditions for twocomponent systems are given in Table $\mathrm{V}$.

\section{Conversion}

During emulsion polymerization, a sample of the emulsion latex was periodically taken out of the reactor, immediately poured into chilled hydroquinone methanol solution, and immersed in an ice bath to quench the reaction. The precipitated polymers were dried in an oven at $40^{\circ} \mathrm{C}$ overnight and then in a vacuum oven at $40^{\circ} \mathrm{C}$ until loss of weight did not change.

The conversion of semi-batch soapless emulsion polymerization was calculated as,

$$
\text { Conversion }=\frac{P}{W \times M \%}
$$

where $P$ is the weight of dry polymer obtained from the sample; $W$ weight of the sample and $M \%$ weight percentage of total monomers already added to the reaction reactor in the reaction mixture.

The conversion of batch soapless emulsion polymerization was determined as,
Table IV. Ingredients and conditions of the two-component system in semi-batch emulsion polymerization

\begin{tabular}{ll} 
MMA Monomer/g & $70(50)$ \\
Styrene Monomer/g & a \\
Initiator $\left(\mathrm{K}_{2} \mathrm{~S}_{2} \mathrm{O}_{8}\right) / \mathrm{g}$ & $30(50)$ \\
Deionized water/g & 1 \\
Stirring rate $/ \mathrm{rpm}$ & 1000 \\
Temperature $/{ }^{\circ} \mathrm{C}$ & 300 \\
Reaction method & 80 or 70 \\
\hline
\end{tabular}

${ }^{a}$ Feed in gradually over time.

Table V. Inredients and conditions of two-component system in batch emulsion polymerization

\begin{tabular}{ll}
\hline MMA Monomer/g & $70(50)$ \\
Styrene Monomer/g & $30(50)$ \\
Initiator $\left(\mathrm{K}_{2} \mathrm{~S}_{2} \mathrm{O}_{8}\right) / g$ & 1 \\
Deionized water/g & 1000 \\
Stirring rate/rpm & 300 \\
Temperature $/{ }^{\circ} \mathrm{C}$ & 80 or 70 \\
Reaction method & Batch \\
\hline
\end{tabular}

$$
\text { Conversion }=\frac{P}{W \times M_{\mathrm{o}} \%}
$$

where $M_{0} \%$ is weight percentage of total monomers initially in the reaction mixture.

\section{Composition of Copolymer}

We analyzed the composition of copolymer using GC and ${ }^{1} \mathrm{H}$ NMR.

Gas Chromatography (GC) Analysis. During emulsion polymerization, a sample of the emulsion latex was taken from the reactor, and each monomer of the latex samples was measured by GC. The gas chromatograph equipped with $14 \%$ cyanopropylphenyl / $86 \%$ dimethyl polysiloxan packed capillary column was used. The temperatures of injector and detector were $200^{\circ} \mathrm{C}$. Initially, column temperature was held at $50^{\circ} \mathrm{C}$ for $4 \mathrm{~min}$, and heated to $160^{\circ} \mathrm{C}$ at a heating rate of $10^{\circ} \mathrm{C} \mathrm{min}{ }^{-1}$.

${ }^{1} \mathrm{H}$ NMR Analysis. ${ }^{1} \mathrm{H}$ NMR spectra of all samples were obtained using a EX-400 NMR spectrometer operated at $399.65 \mathrm{MHz}$ in $\mathrm{CDCl}_{3}$ at $25^{\circ} \mathrm{C}$.

In the PMMA ${ }^{1} \mathrm{H}$ NMR spectrum, we observed $\alpha-\mathrm{CH}_{3}$, methylene and methoxy proton $\left(-\mathrm{OCH}_{3}\right)$ resonance. In the PS ${ }^{1} \mathrm{H}$ NMR spectrum, we observed resonance of aryl, methylene and methine protons.

\section{Analysis of Molecular Weight}

Weight average and number average molecular weights of polymers were measured by the gel permeation chromatography (GPC Model SE-61).

\section{RESULTS AND DISCUSSION}

The MMA/Styrene tow-component system was studied by soapless semi-batch emulsion copolymerization and soapless batch emulsion copolymerization reactions.

Optimal monomer feed flow rates were determined from experiment and theory through the semi-batch emulsion polymerization, and instantaneous composition of the polymer was effectively controlled to get the desired final product. 


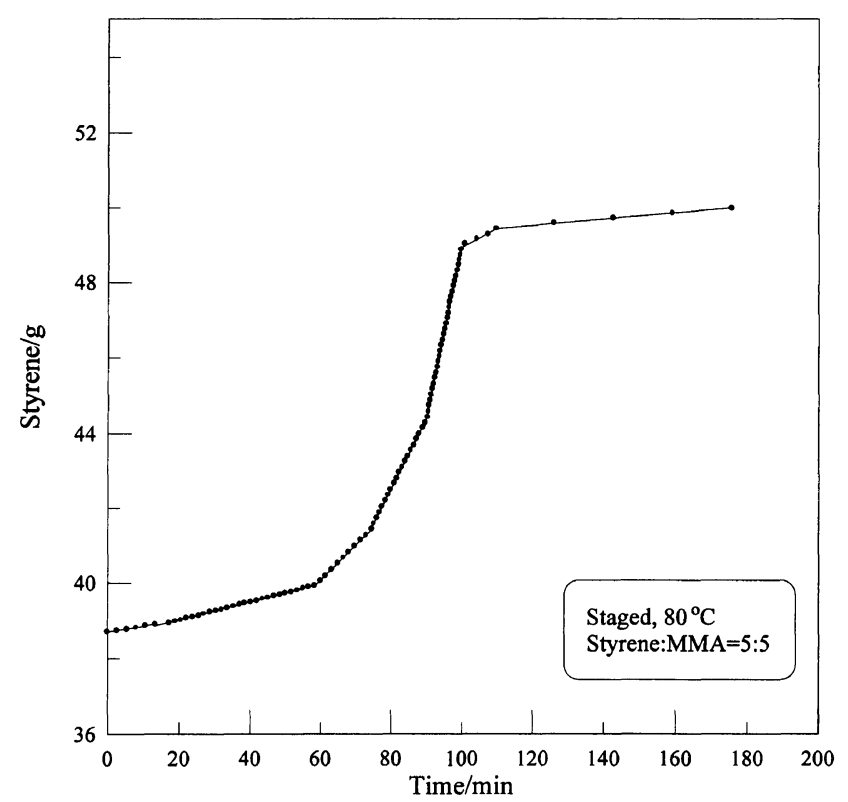

Figure 2. Monomer feed flow rate vs. time for semi-batch reaction of Styrene and MMA with weight ratio of 5:5.

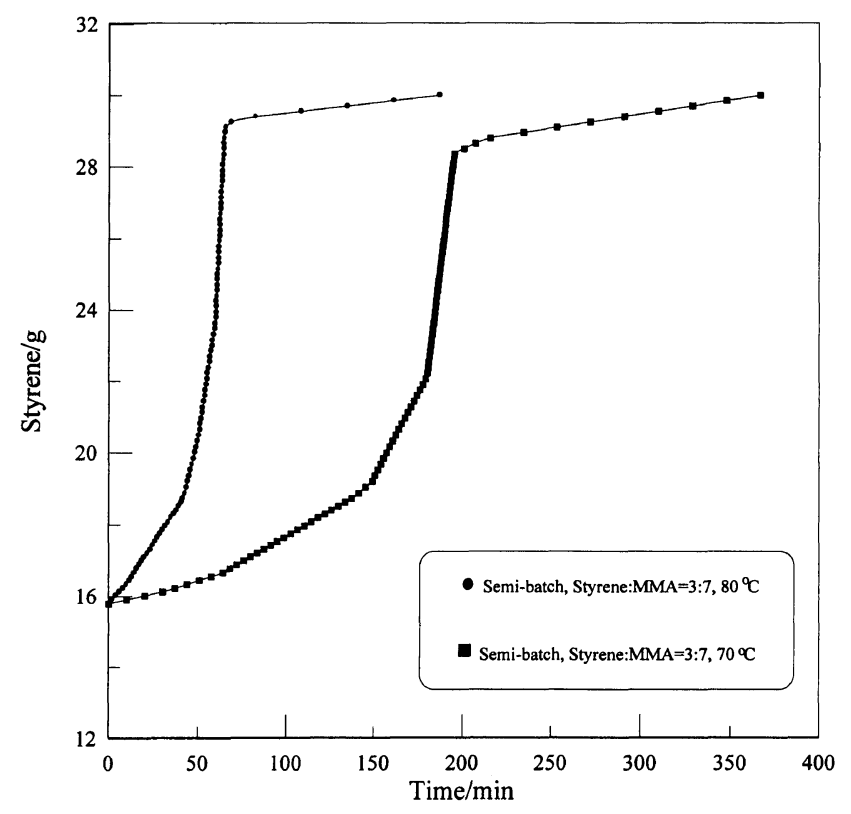

Figure 3. Styrene monomer feed flow rate $v s$. time for semibatch reaction of Styrene and MMA with weight ratio of 3:7.

\section{Monomer Feed Flow Rate}

Figures 2 and 3 show the results of the optimal monomer feed flow rate obtained by experiment of conversion $v s$. time and theory of semi-batch emulsion polymerization, eqs 4 and 9 . Figures 4 and 5 showed conversion $v$ s. time for soapless semi-batch emulsion copolymerization reaction based on optimal monomer feed flow rate. They show that the experimental results well match theoretical values. The experimental data corresponded to theoretical values only after three or four trials.

\section{Composition of the Copolymer}

We analyzed the composition of copolymer using GC

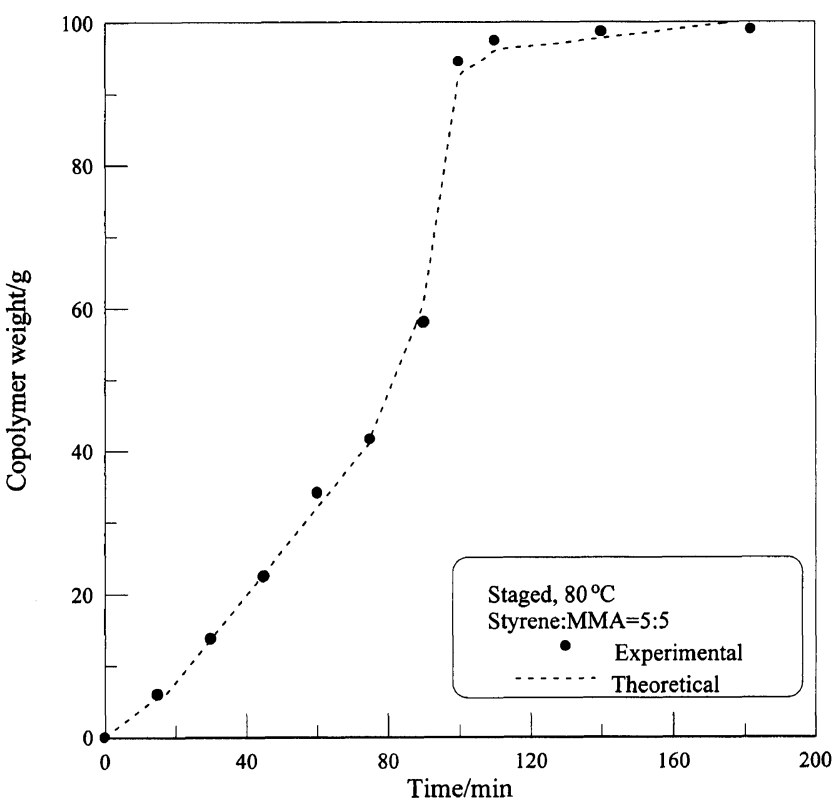

Figure 4. Conversion vs. time for semi-batch reaction of Styrene and MMA with weight ratio of 5:5.

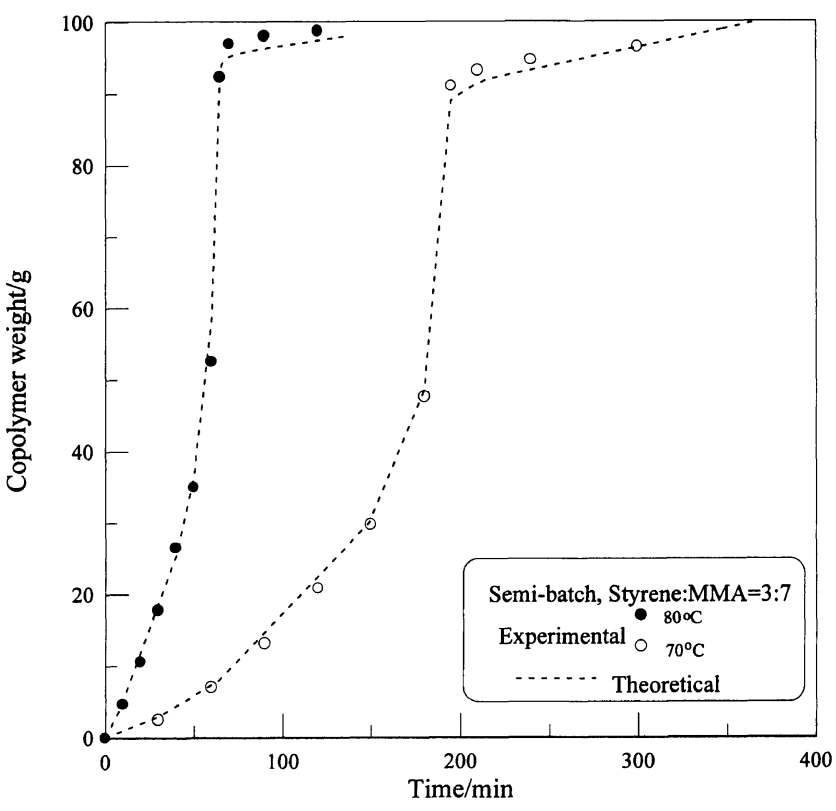

Figure 5. Conversion $v$ s. time for semi-batch reaction of Styrene and MMA with weight ratio of 3:7.

and ${ }^{1} \mathrm{H}$ NMR.

\section{GC Analysis}

Copolymer composition was estimated from the composition of the residual monomer mixture using material balance. We used GC to measure the compositions of monomer mixtures of latex samples. The results of the GC analysis are shown in Figures 6 and 7. Final compositions of copolymers synthesized by semi-batch copolymerization well matched the theoretical values except for low-conversion conditions, while those by batch copolymerization showed deviation from theoretical values. When conversion was low, the corresponding ex- 


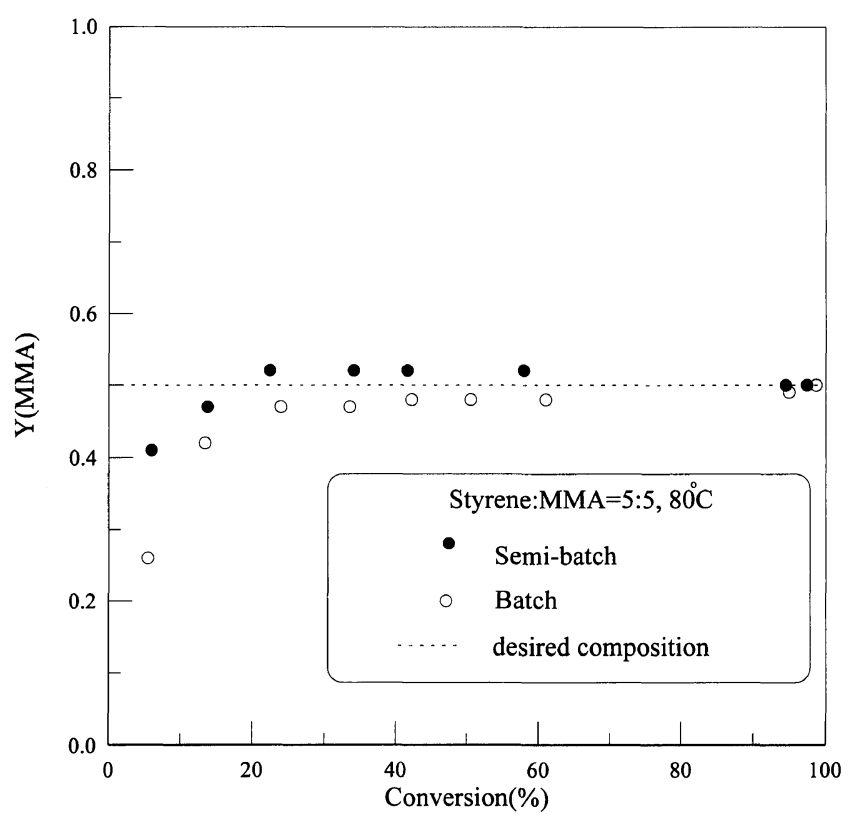

Figure 6. GC results of polymer composition vs. conversion for emulsion copolymerization of Styrene and MMA with weight ratio of $5: 5$.

perimental data were lower than theoretical values in both batch and semi-batch reactions. Because there were more monomers in the system that accounted for oilwater phase separation when conversion was low, and error may be generated for more monomers of emulsion samples.

\section{${ }^{1} H$ NMR Analysis}

${ }^{1} \mathrm{H}$ NMR Analysis of Polymers. ${ }^{1} \mathrm{H}$ NMR spectra of PMMA and PS are shown in Figures 8 and 9 respectively.

In Figure 8 of the PMMA ${ }^{1} \mathrm{H}$ NMR spectrum, resonance at $0.76-1.15 \mathrm{ppm}$ was due to $\alpha-\mathrm{CH}_{3}$ protons. Methylene proton resonance was at $1.29-1.35 \mathrm{ppm}$ and $1.72-1.98 \mathrm{ppm}$, and the methoxy $\left(-\mathrm{OCH}_{3}\right)$ resonance appeared at $3.51 \mathrm{ppm}$. In Figure 9, the PS ${ }^{1} \mathrm{H}$ NMR spectrum, resonance due to aryl protons was observed at $6.46-7.24 \mathrm{ppm}$, and methylene and methine proton resonance was at $1.42 \mathrm{ppm}$ and $1.84 \mathrm{ppm}$.

\section{Composition of Copolymers}

We determined the compositions of copolymer using the resonance peak areas of copolymers from ${ }^{1} \mathrm{H}$ NMR spectra. In the two component system of MMA/Styrene, copolymer compositions were determined by spectral integration of aryl and methoxy protons because of large differences in values of chemical shifts for the two protons. Therefore, the MMA mole fraction in the copolymer may be determined as,

$$
F(\mathrm{MMA})=\frac{5 I\left(-\mathrm{OCH}_{3}\right)}{5 I\left(-\mathrm{OCH}_{3}\right)+3 I(-a r y l)}
$$

where $I\left(-\mathrm{OCH}_{3}\right)$ and $I(-a r y l)$ are peak intensities of $-\mathrm{OCH}_{3}$ and aryl proton resonances repectively.

The ${ }^{1} \mathrm{H}$ NMR spectrum of the copolymer in an MMA/

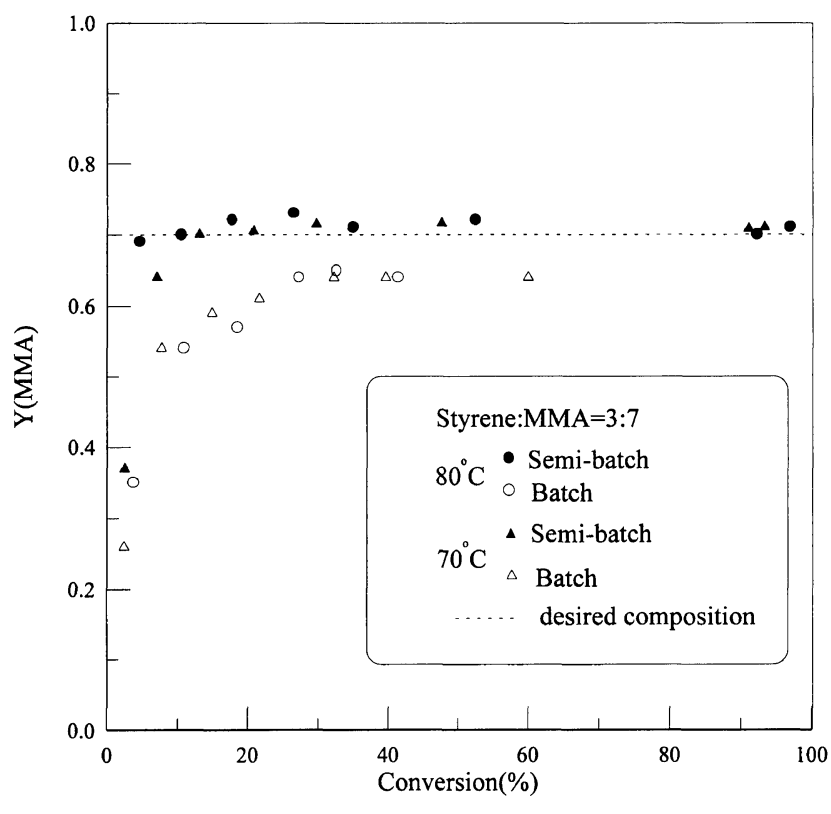

Figure 7. GC results of polymer composition $v s$. conversion for emulsion copolymerization of Styrene and MMA with weight ratio of $3: 7$.

Styrene system is shown in Figure 10. Methoxy $\left(-\mathrm{OCH}_{3}\right)$ proton resonance appeared at $2.43-3.56 \mathrm{ppm}$, and resonance at $6.95-7.14 \mathrm{ppm}$ was due to aryl protons. We then determined the composition of the copolymer, and confirmed that Styrene and MMA form the copolymers.

We then determined compositions of the copolymers using the underlying area of the spectrum along with mole balance.

Figures 11 and 12 show composition $v s$. conversion by ${ }^{1} \mathrm{H}$ NMR analysis for copolymers synthesized under different reaction conditions. The figures have the same conclusion as GC analysis, which illustrates that the copolymer composition is effectively controlled through semi-batch reaction, and ensures constant composition that meet requirements throughout the entire reaction. In the two-component system of MMA/Styrene, when the weight ratio of the two monomers was $5: 5$, the results matched well theoretical values for copolymers from batch and semi-batch reactions, because the 5 to 5 weight ratio of monomers created an azeotropic system, where instantaneous composition of the polymer is the same as the monomer mixture. The 5:5 weight ratio of the copolymer may be obtained without control of monomer feeding. In this case, there were no differences between semi-batch and batch copolymerization reactions.

\section{Analysis of Molecular Weight}

Analysis of molecular weight by GPC is summarized in Table VI. In general, average molecular weight was lower at higher reaction temperature. A similar molecular weight distribution was observed for semi-batch and batch reaction systems.

\section{CONCLUSION}

This research studies the MMA/Styrene towcomponent system through soapless semi-batch emul- 
<smiles>CCC(C)(C)C(=O)OC</smiles>

\begin{tabular}{|c|c|}
\hline \multicolumn{2}{|c|}{ Assignments(No. of protons) } \\
\hline $\mathrm{a}$ & $1.29-1.98(2)$ \\
\hline $\mathrm{b}$ & $0.76-1.15(3)$ \\
\hline $\mathrm{c}$ & $3.51(3)$ \\
\hline
\end{tabular}

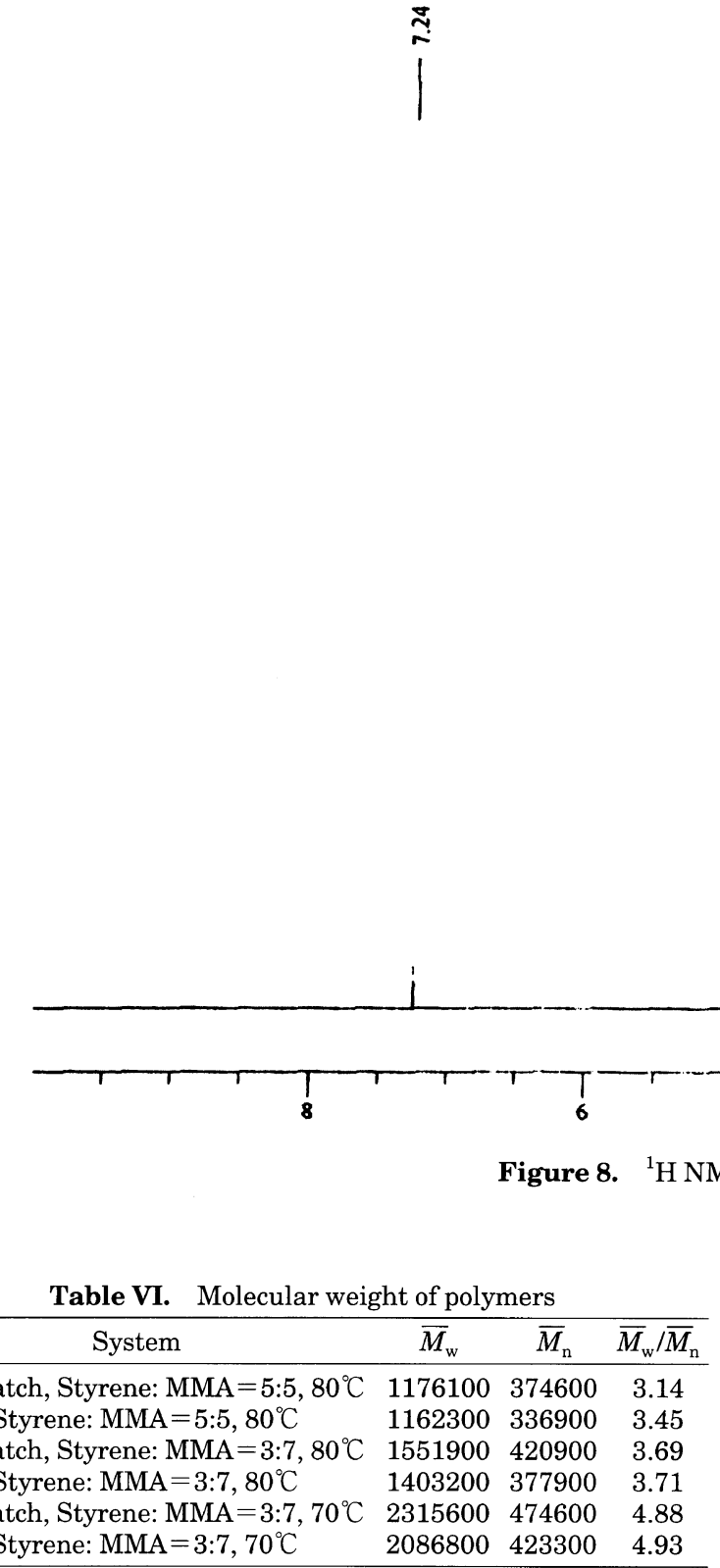

sion copolymerization and soapless batch emulsion copolymerization reactions.

The optimal monomer feed flow rate was obtained by only after three or four trials. From conversions of semibatch and batch copolymerization reactions, we found that increasing reaction temperature or composition of

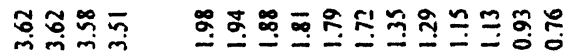

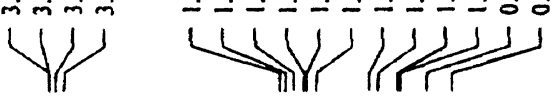

PPM

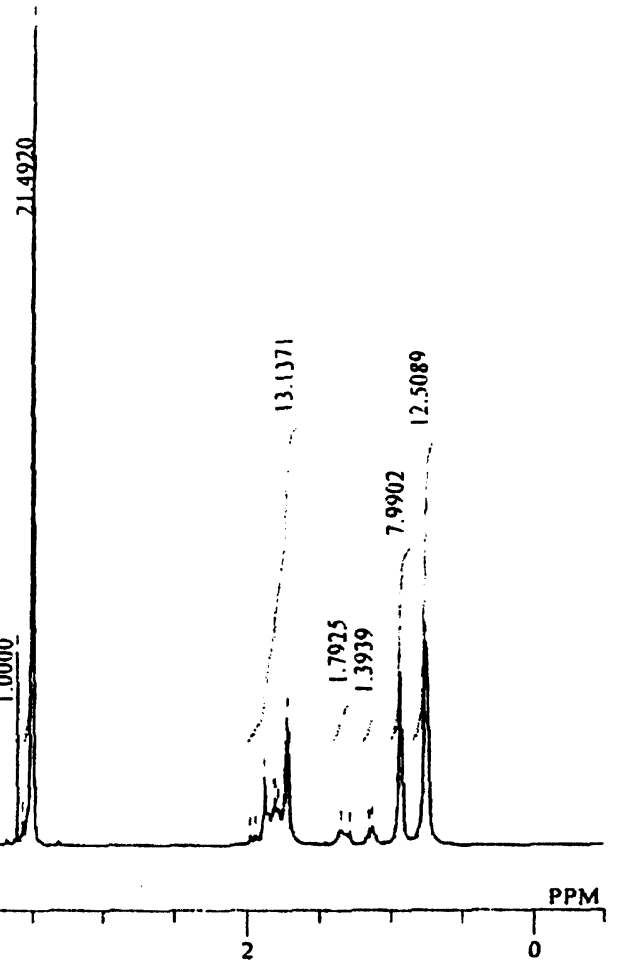

m of PMMA.

MMA increased the reaction rate.

From the results of GC and ${ }^{1} \mathrm{H}$ NMR, we effectively controlled the instantaneous composition of the polymers through semi-batch emulsion polymerization, and had it fixed throughout the entire reaction.

From molecular weight, average molecular weight was lower with higher reaction temperature. Similar molecular weight distribution was observed for semibatch and batch reaction systems.

\section{REFERENCES}

1. J. Snuparek and F. Krska, J. Appl. Polym. Sci., 21, 2253 (1977).

2. J. Snuparek and F. Krska, J. Appl. Polym. Sci., 26, 4081 (1968). 


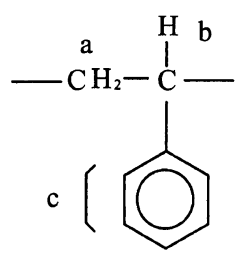

\begin{tabular}{|c|c|}
\hline \multicolumn{2}{|c|}{ Assignments(No. of protons) } \\
\hline $\mathrm{a}$ & $1.42(2)$ \\
\hline $\mathrm{b}$ & $1.84(1)$ \\
\hline $\mathrm{c}$ & $6.46-7.24(5)$ \\
\hline
\end{tabular}

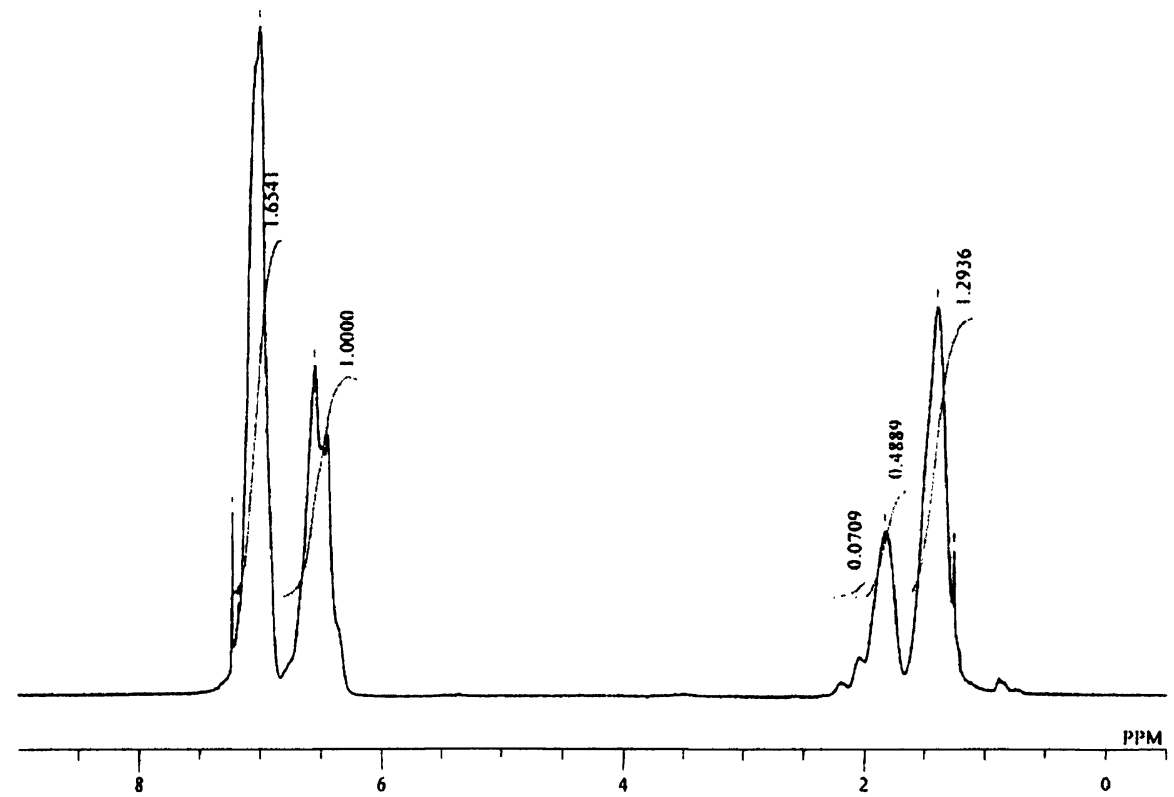

Figure 9. ${ }^{1} \mathrm{H}$ NMR spectrum of PS.

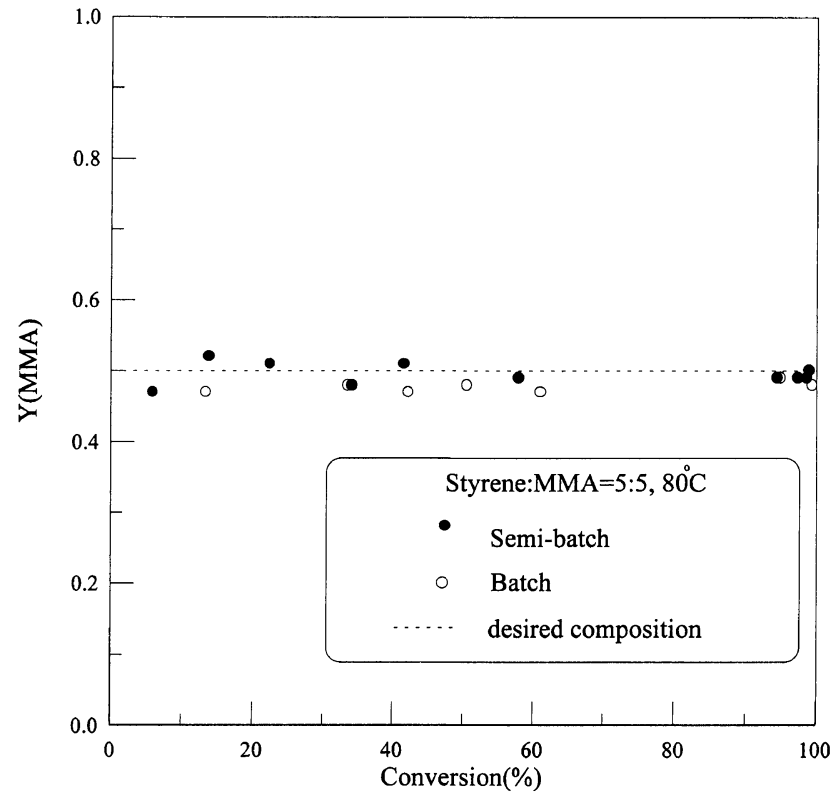

Figure 11. ${ }^{1} \mathrm{H}$ NMR results of polymer composition vs. conversion for emulsion copolymerization of Styrene and MMA with weight ratio of 5:5.

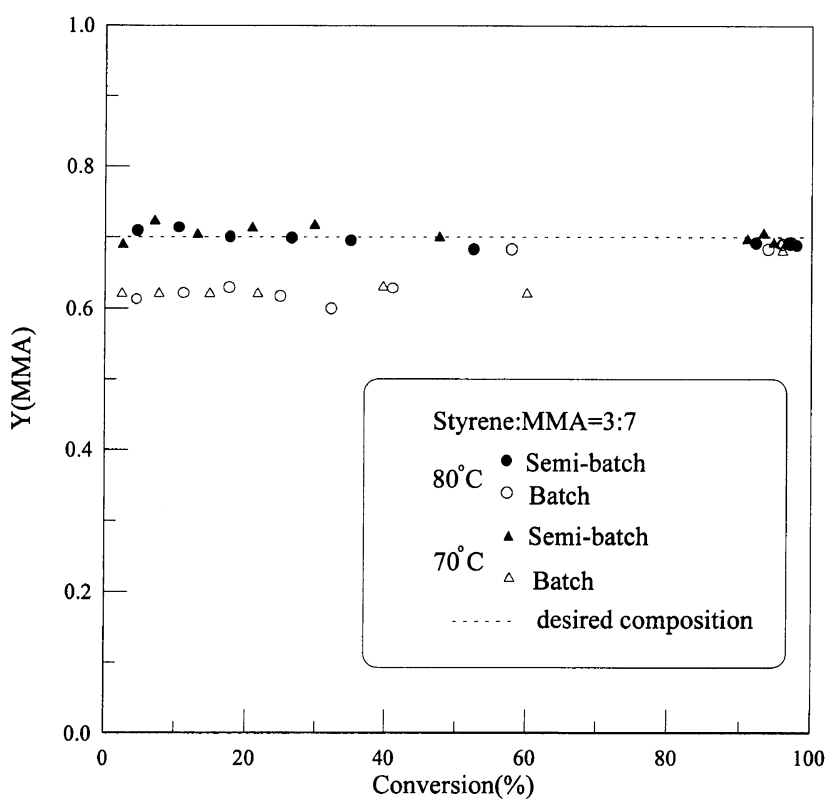

Figure 12. ${ }^{1} \mathrm{H}$ NMR results of polymer composition vs. conversion for emulsion copolymerization of Styrene and MMA with weight ratio of $3: 7$. 
cieoy-10

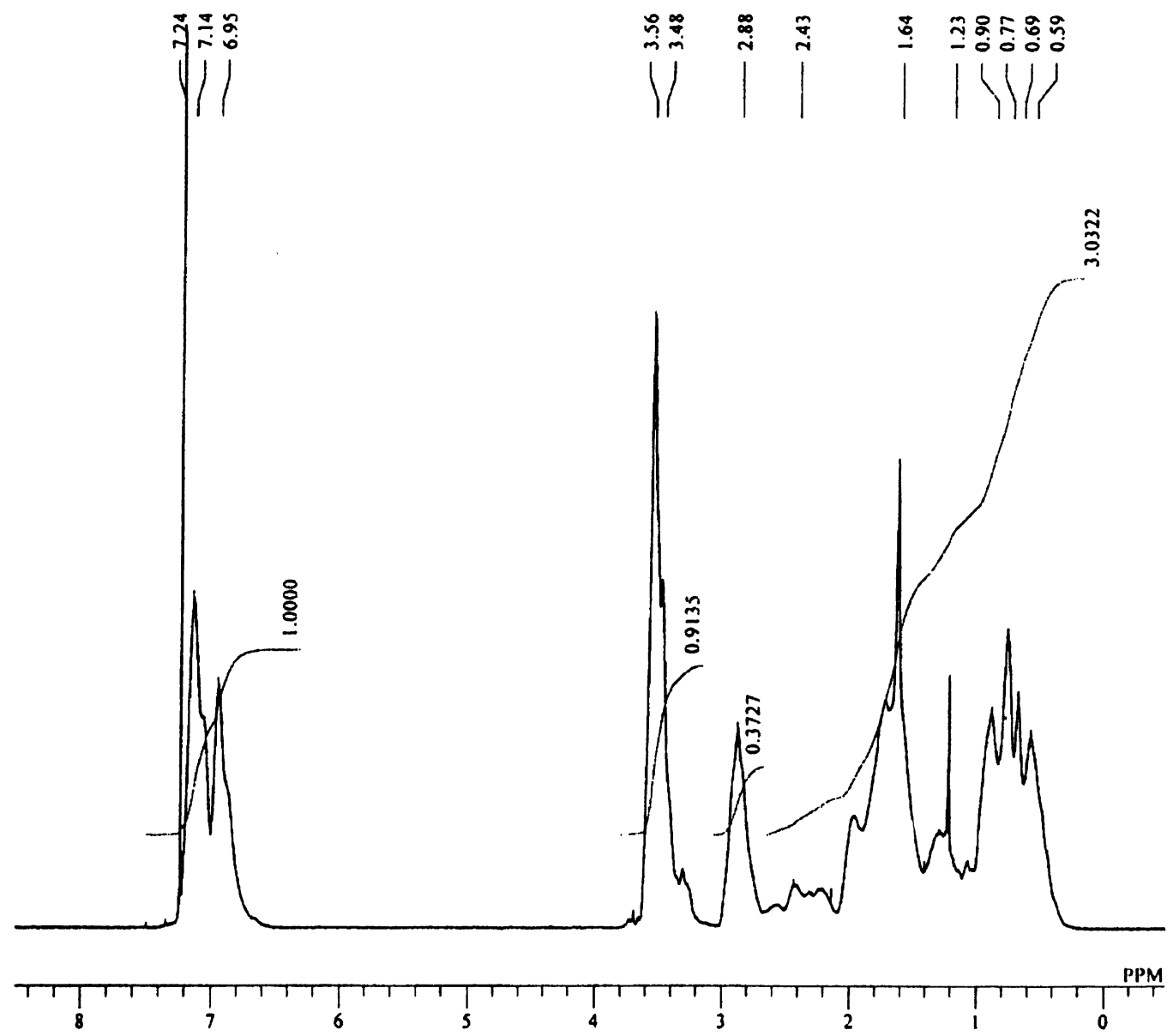

Figure 10. ${ }^{1} \mathrm{H}$ NMR spectrum of Styrene-MMA copolymer.

3. D. R. Basset and K. L. Hoy, in "Process Description and Polymer Properties in Emulsion Polymers and Emulsion Polymerization", D. R. Basset and A. E. Hamielec, Ed., ACS Symposium Series 165, American Chemical Society, Washington, DC, 1981.

4. M. S. El-Aasser, T. Makgawinata, J. W. Vanderhoff, and C. Pichot, J. of Polym. Sci. Polym. Chem. Ed ., 21, 2363 (1983).

5. S. C. Mira, C. Pichot, M. S. El-Aasser, and J. W. Vanderhoff, J. Polym. Sci. Polym. Chem. Ed., 21, 2383 (1983).

6. J. Dimitratos, C. Georgakis, M. S. El-Aasser, and A. Klein, Comp. Chem. Eng., 13, 21 (1989).

7. J. Dimitratos, C. Georgakis, M. S. El-Aasser, and A. Klein,
Chem. Eng. Sci., 46, 3203 (1991).

8. G. Arzamendi and J. M. Asua, Makromol. Chem. Macromol. Symp., 35/36, 249 (1990).

9. G. H. J. Van Doremaele, H. A. S. Schoonbrood, J. Kurja, and A. L. German, J. Appl. Polym. Sci., 45, 957 (1992).

10. P. Canu, S. Canegallo, G. Storti, and M. Morbidelli, J. Appl. Polym. Sci., 54, 1899 (1994).

11. S. Canegallo, P. Canu, G. Storti, M. Morbidelli, and G. Storti, J. Appl. Polym. Sci., 54, 1919 (1994).

12. J. Brandrup and E. H. Immergut, Polymer Handbook, 3rd ed., John Wiley \& Sons, New York, N.Y., 1989.

13. J. L. Gardon, J. Polym. Sci., 6, 2859 (1968). 